\title{
Roll Deformation Model of Four High Hot Rolling Mills Based on Im- proved Influence Function Method
}

\author{
Shao Jian ${ }^{1, *}$, Li Bo $^{1}$, He Anrui ${ }^{1}$, Sun Wenquan ${ }^{1}$, Liu Zhubin ${ }^{2}$ and Zhou Jie ${ }^{2}$ \\ ${ }^{I}$ National Engineering Research Center of Advanced Rolling Technology, University of Science and Technology \\ Beijing, Beijing, China \\ ${ }^{2}$ Hot Strip Mill of Valin LianYuan Steel Co., Ltd, Loudi, China
}

\begin{abstract}
Roll deformation is an important part of profile and flatness control system. Computation speed and accuracy of roll deformation model is a research hotspot, which provides a precondition for online application. This paper puts forward a new roll deformation model of four high hot rolling mills based on improved influence function method. In the new model, the roll bending calculation uses elastic beam method based on the mechanics of materials theory, which avoids complex algorithms for solving influence coefficient matrix. The relationship between roll flattening and rolling force is fitted by quartic polynomial, which avoids complex iteration algorithm because of their nonlinear relationship. In iteration process of deformation coordination equation, element flattening difference and center flattening correction model are developed, which avoids calculation efficiency problem due to double iterative in the influence function method. By comparison with the finite element method and influence function method, the new model has faster calculation speed and higher precision, which satisfies the online application requirement, and provides the guarantee for high precision quality control.
\end{abstract}

Keywords: Influence function method, Profile and flatness control, Roll bending, Roll deformation, Roll flattening.

\section{INTRODUCTION}

Roll deformation is the core model of profile and flatness control system, which can calculate work roll and backup roll deformation behavior under various conditions and get desired profile at the exit of mills [1]. Due to the computation speed and accuracy limiting conditions, there is lack of roll deformation model online application, and offline models for roll deformation calculation are widely used, such as finite element method [2], influence function method [3], two dimensional varying thickness finite element model and so on [4]. The online linear model can be achieved by fitting offline calculation results. According to the influence of roll wear and thermal expansion, the actual roll contour is more complex and linear model cannot describe roll transverse data, which will bring calculation errors, and restrict the accuracy of profile and flatness control system under strip specification changing, including steel, thickness, and width.

Finite element method (FEM) and influence function method are popular for roll deformation calculation. FEM has few assumptions and high precision, but need considerable operational time and usually is used for offline calculation. The influence function method was put forward by K.N.Shohet who introduced Green function concept of

\footnotetext{
*Address correspondence to this author at the XueYuan Road, Beijing, China. Postcard: 100083; Tel: +86 13810014743; E-mail: ustbshao@163.com
}

mathematics into thin strip transverse thickness distribution calculation [5]. The basic idea of influence function method is to discrete roll, load and elastic deformation. Determine each element deformation caused by load on each element and stack the element deformation, and then get the thickness distribution after rolling. Montmitonnet used FEM for hot and cold strip rolling process simulation. Among them rolls bending and flattening were calculated by influence function method [6]. Salimi used influence function method for roll deformation calculation based on beam model [7]. Liu also used influence function method for roll deformation [8]. Although the running speed of influence function method is greatly improved, online calculation is still difficult.

In order to improve shape setup precision and model adaptability in strip specification changing, online calculation of roll elastic deformation will be the development direction. Based on conventional influence function method, roll bending model, roll flattening model and deformation coordination equation are improved for better running efficiency and precision.

\section{DISCRETIZATION FOR DEFORMATION}

\subsection{Roll Discretization}

Based on rolling center line, work roll and backup roll are divided into halves, each half of the roll deformation is 


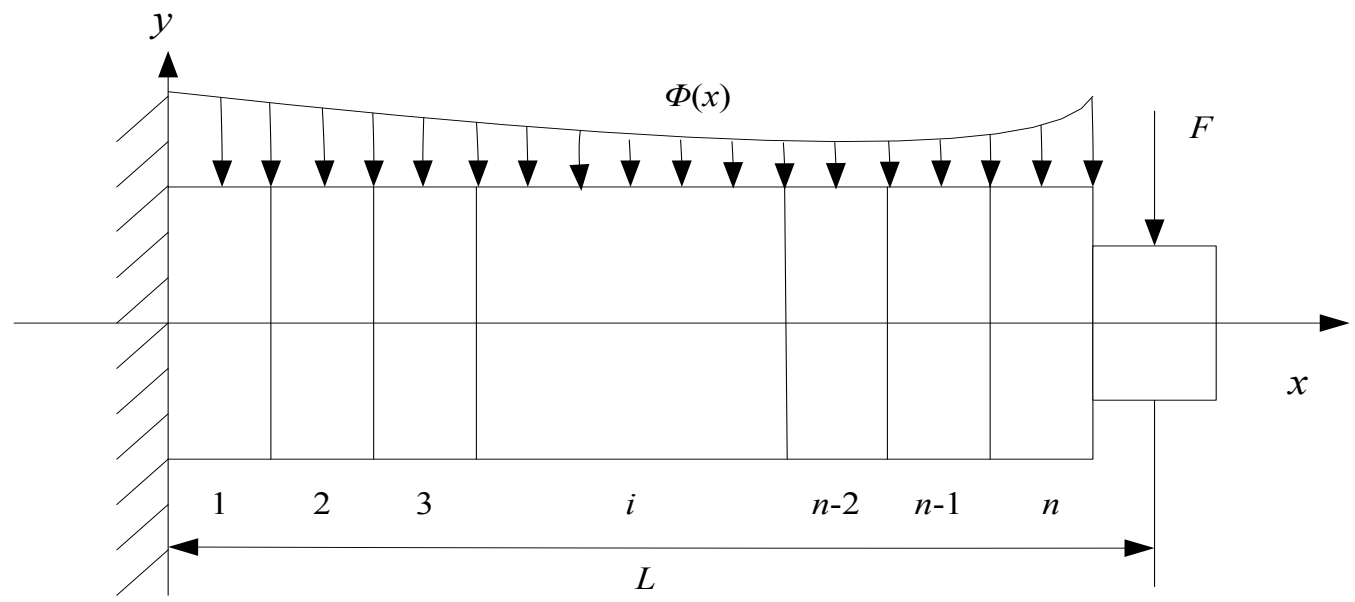

Fig. (1). Simplified cantilever beam model of roll.

calculated, and the results are combined into the whole roll system. In order to ensure one to one correspondence between work roll and backup roll element, element division method of the two rolls are the same. Taking the rolling center line section as interface, half of roll can be abstracted as a cantilever beam, as shown in Fig. (1). Where $x$ is the roll axial coordination, $y$ is the roll radial coordinate, $n$ is the total element number, $i$ is the element number, $F$ is the concentrated force, $\varphi(x)$ is the distributed force, and $L$ is the beam Length.

Upward displacement of upper roll is positive, lower roll is opposite, and positive force direction generates positive displacement. Half of roll length along the axial direction is discretized into a number of elements, each element is labeled as $1,2,3 \ldots$ and $n$.

$x_{i}=x_{i-1}+\Delta x_{i} \quad i=1 \sim n$

Where, $x_{i}$ is the roll element axial coordination, $\Delta x_{i}$ is the length of $i$ element, $x_{0}=0$, and $\Delta x_{0}=0$. By defining backup roll uniform element, each element length is the same and can be expressed as follows:

$\Delta x=L_{b} / 2 n, x_{i}=i \Delta x$

Where, $\Delta x$ is the uniform element length, $L_{\mathrm{b}}$ is the backup roll length. In element $1,2 \ldots$ and $n$, work roll contacts with backup roll. In element $1,2 \ldots$ and $\mathrm{m}$, work roll contacts with strip, $\mathrm{m}$ can be calculated as follows:

$m=B / 2 \Delta x$

Where $B$ is strip width.

\subsection{Load Discretization}

Usually, work roll and backup roll are also under concentrated load and distributed load, although the loads size and distribution are not the same, they can be unified with a distributed force $\varphi(x)$ and a concentrated force $F$. According to upper work roll: $\left\{\begin{array}{l}\varphi(x)=p(x)-q(x) \\ F=F_{w} \\ L=L_{f} / 2 \pm S_{f}\end{array}\right.$

According to upper backup roll:

$\left\{\begin{array}{l}\varphi(x)=q(x) \\ F=-P_{b} \\ L=L_{h} / 2\end{array}\right.$

Where $q(x)$ is the axial contact pressure between work roll and backup roll, $p(x)$ is the axial rolling force distribution, $F_{\mathrm{w}}$ is the work roll bending force per side, $P_{\mathrm{b}}$ is the rolling force per side, $L_{f}$ is the distance between bending force action point on two sides, $L_{\mathrm{h}}$ is the distance between rolling force action point on two sides, $S_{f}$ is the work roll shifting width; defining shifting to operation side for positive.

Discretization of $\varphi(x)$ is the same as roll discretization, the distribution pressure of each element can be expressed as concentrated force $\varphi_{i}$.

$\varphi_{i}=\varphi\left(x_{i}\right) \Delta x \quad i=1 \sim n$

For work roll and backup roll, $\varphi_{i}$ is calculated as follows:

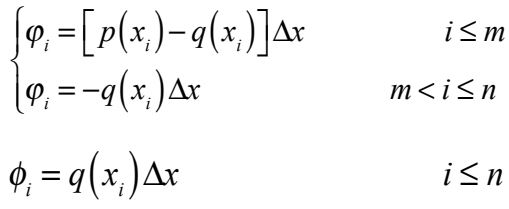

\section{ROLL BENDING BASED ON ELASTIC BEAM METHOD}

In influence function method, complex influence coefficient matrix is calculated for roll bending, which needs considerable running time. Along with the increase of iterations 


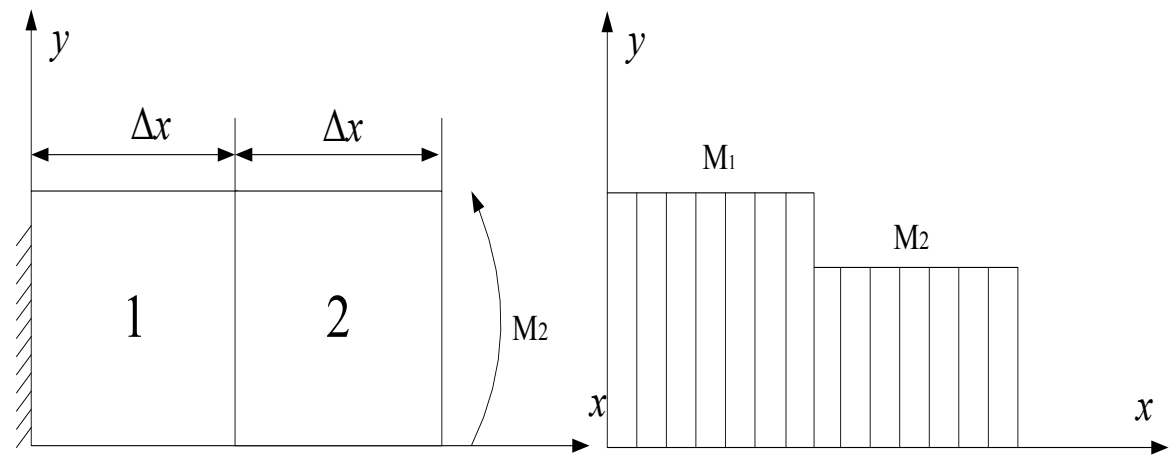

Fig. (2). Elements 1 and 2 bending moment diagram not considering shear stress.

and roll partition numbers, roll bending calculation will become the bottleneck of roll deformation model online application. In this paper, roll axis deformation replaced larger dimension deformation by using elastic beam method. According to beam bending theory, bending moment and shear stress are both considered in larger size beam.

Elements 1 and 2 bending moment diagram not considering shear stress is shown in Fig. (2).

If only considering bending moment, each element bending can be expressed as follows:

$y_{i+1}=y_{i}+\frac{M_{1}+M_{2}+\cdots+M_{i}}{E I} \Delta x^{2}+\frac{M_{i+1}}{2 E I} \Delta x^{2}$

Where $y_{i}$ is roll bending of $i$ element caused by moment, $M_{i}$ is the bending moment of $\mathrm{i}$ element, $E$ is the Young modulus of roll, $I$ is the inertia moment of roll section.

If only considering shear force, each element bending can be expressed as follows:

$y_{s i+1}=y_{s i}+\frac{\alpha_{s} Q_{i}}{G A} \Delta x$

Where $y_{s i}$ is roll bending of $i$ element caused by shear force, $Q_{i}$ is the shear force of $i$ element, $\alpha_{\mathrm{s}}$ is the shear coefficients, $G$ is the shear modulus, $A$ is the roll section area.

The total bending $y^{\prime}$ can be obtained by combining the moment effect with shear force. For the $i+1$ element, total bending is calculated as follows:

$$
\begin{aligned}
y_{i+1}^{\prime}= & y_{i+1}+y_{s i+1} \\
= & y_{i}+\frac{M_{1}+M_{2}+\cdots+M_{i}}{E I} \Delta x^{2} \\
& +\frac{M_{i+1}}{2 E I} \Delta x^{2}+y_{s i}+\frac{\alpha_{s} Q_{i}}{G A} \Delta x \\
= & y_{i}+y_{s i}+\frac{M_{1}+M_{2}+\cdots+M_{i}}{E I} \Delta x^{2} \\
& +\frac{M_{i+1}}{2 E I} \Delta x^{2}+\frac{\alpha_{s} Q_{i}}{G A} \Delta x \\
= & y_{i}^{\prime}+\frac{M_{1}+M_{2}+\cdots+M_{i}}{E I} \Delta x^{2} \\
& +\frac{M_{i+1}}{2 E I} \Delta x^{2}+\frac{\alpha_{s} Q_{i}}{G A} \Delta x
\end{aligned}
$$

According to beam bending model, each element bending moment $M(i)$ can be expressed as below:

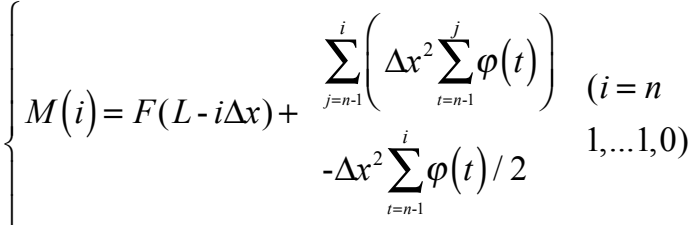

$$
\begin{aligned}
& M(i)=F(L-i \Delta x) \quad(i=n)
\end{aligned}
$$

Each element shear force can be expressed as below:

$Q(i)=\frac{M(i-1)-M(i)}{\Delta x} \quad(i=1,2, \ldots n)$

The above roll bending calculation method based on elastic beam is suitable for work roll and backup roll with different boundary conditions, such as roll length, roll diameter, elastic modulus, moment of inertia, cross section area and so on. In order to verify new model accuracy, roll bending results were compared by elastic beam method and influence function method. Comparison result shows that the maximum error between the two methods is $6.39 \%$, and computing speed and accuracy can be guaranteed.

\section{ROLL ELASTIC FLATTENING}

In roll elastic deformation theory, contact flattening of work roll and backup roll usually were considered two infinite long cylinder contact problems. The half of contact width is given by Hertz as follows [9]:

$b=\sqrt{\frac{4}{\pi} q\left(\frac{1-v_{1}^{2}}{E_{1}}+\frac{1-v_{2}^{2}}{E_{2}}\right) \frac{R_{1} R_{2}}{R_{1}+R_{2}}}$

Where $q$ is the contact pressure of roll contact area, $v_{1}$ and $v_{2}$ are the two cylinders Poisson ratio, respectively, $E_{1}$ and $E_{2}$ are the two cylinders Young modulus, respectively, and $R_{1}$ and $R_{2}$ are the two cylinders radius, respectively. Based on Hertz theory, Foppl gave the flattening w caused by contact pressure under the same cylinder material:

$$
w=\frac{2 q\left(1-v^{2}\right)}{\pi E}\left(\frac{2}{3}+\ln \frac{2 R_{1}}{b}+\ln \frac{2 R_{2}}{b}\right)
$$




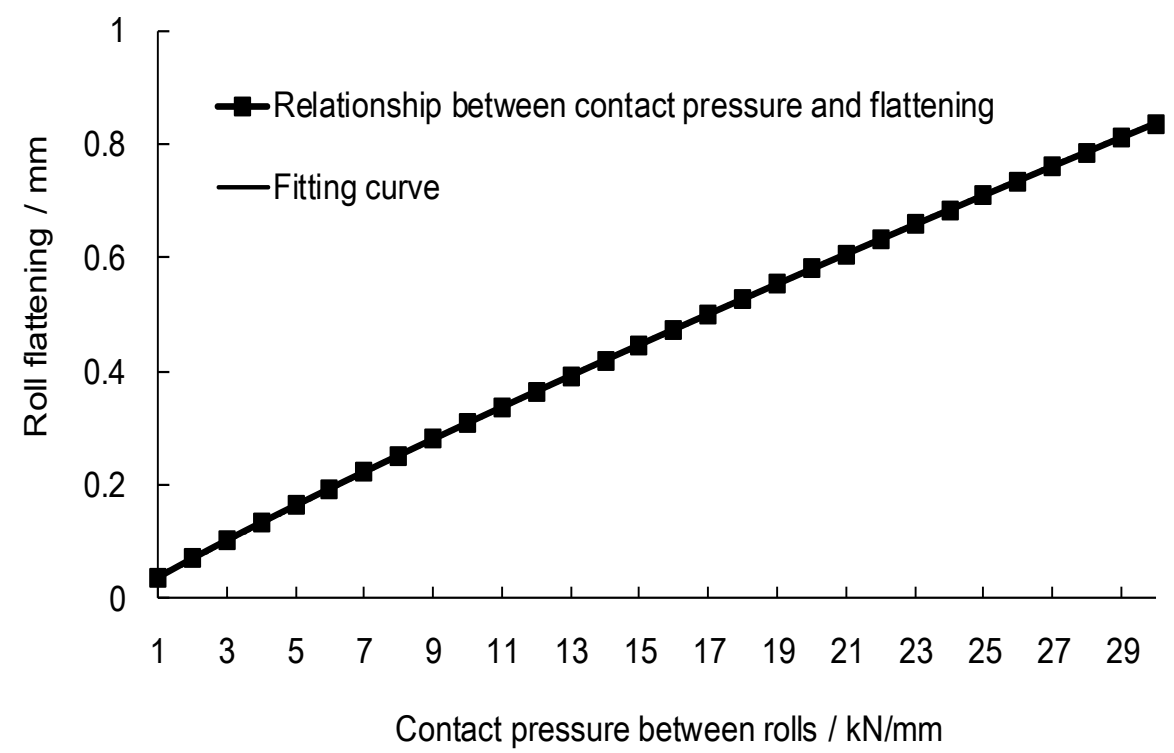

Fig. (3). Relationship between contact pressure and flattening and fitting result.

From equations (13) and (14), $w$ can also be expressed as follows:

$$
w=\frac{2 q\left(1-v^{2}\right)}{\pi E}\left(\ln \frac{\pi \sqrt[3]{q^{2}} E}{4\left(1-v^{2}\right)}+\ln \left(2 R_{1}+2 R_{2}\right)-\ln q\right)
$$

As shown in equation (15), the relationship between roll flattening and contact pressure is nonlinear, and contact pressure calculation needs iteration method when flattening is known, as shown in equation (16):

$$
q=\frac{\pi E w}{2\left(1-v^{2}\right)\left(\ln \frac{\pi \sqrt[3]{q^{2}} E}{4\left(1-v^{2}\right)}+\ln \left(2 R_{1}+2 R_{2}\right)-\ln q\right)}
$$

In iterative process, a hypothesis contact pressure is used for roll flattening and new contact pressure in equation (16). If the error between hypothesis contact pressure and new contact pressure reaches a small value, iterative process is stopped. Considering the complex iterative process and online application, the relationship between roll flattening and contact pressure is fitted by quartic polynomial.

According to the actual production data, $\mathrm{q}$ is in the range of $[1,30] \mathrm{kN}, v_{1}=v_{2}=0.3$, work roll diameter $D_{\mathrm{w}}=780 \mathrm{~mm}$, backup roll diameter $D_{\mathrm{b}}=1520 \mathrm{~mm}$, work roll and backup roll Young modulus are also $210 \mathrm{GPa}$. The relationship between $q$ and $w$ in the above conditions is calculated and fitted by quartic polynomial as shown in equations (17) and (18), and Fig. (3) shows the relationship and fitting result.

$$
\begin{aligned}
& w=4.714 \mathrm{E}-3+3.37 \mathrm{E}-2 q-4.23 \mathrm{E}-3 q^{2} \\
& +1.16 \mathrm{E}-5 q^{3}-1.3745 \mathrm{E}-7 q^{4} \\
& q=-0.1105+28.856 w+15.948 w^{2} \\
& -13.407 w^{3}+5.3938 w^{4}
\end{aligned}
$$

\section{FLATTENING BETWEEN WORK ROLL AND STRIP}

Rolling force in contact area made the work roll flattening, due to the uneven distribution rolling force, flattening is also inhomogeneous, which will affect the strip profile. In strip edge, rolling force changes rapidly and leads to small roll flattening.

Because of the difference condition in both roll sides, flattening calculation result between work roll and strip will become larger than actual data by using infinite long cylinder contact model. The flattening between work roll and backup roll is also larger on both sides which is beyond strip and makes little influence on strip profile. In this paper, influence function method is used for flattening calculation between work roll and strip.

$$
Y_{w s}=G_{w s} P
$$

Where, $Y_{\mathrm{ws}}$ is each element's flattening matrix, $\mathrm{P}$ is each element's rolling force matrix, $G_{\mathrm{ws}}$ is the work roll elastic flattening influence coefficient matrix calculated by improved half space model which can be expressed as follows [10]:

$$
G_{w s}=\left[\begin{array}{ccc}
g_{w s}(1,1) & \cdots & g_{w s}(1, n) \\
\vdots & \ddots & \vdots \\
g_{w s}(n, 1) & \cdots & g_{w s}(n, n)
\end{array}\right]
$$

\section{ITERATIVE CALCULATION OF ROLL DE- FORMATION}

\subsection{Roll Force Equivalent}

Total rolling force is easy to calculate and collect, but rolling force axial distribution is difficult to achieve. 


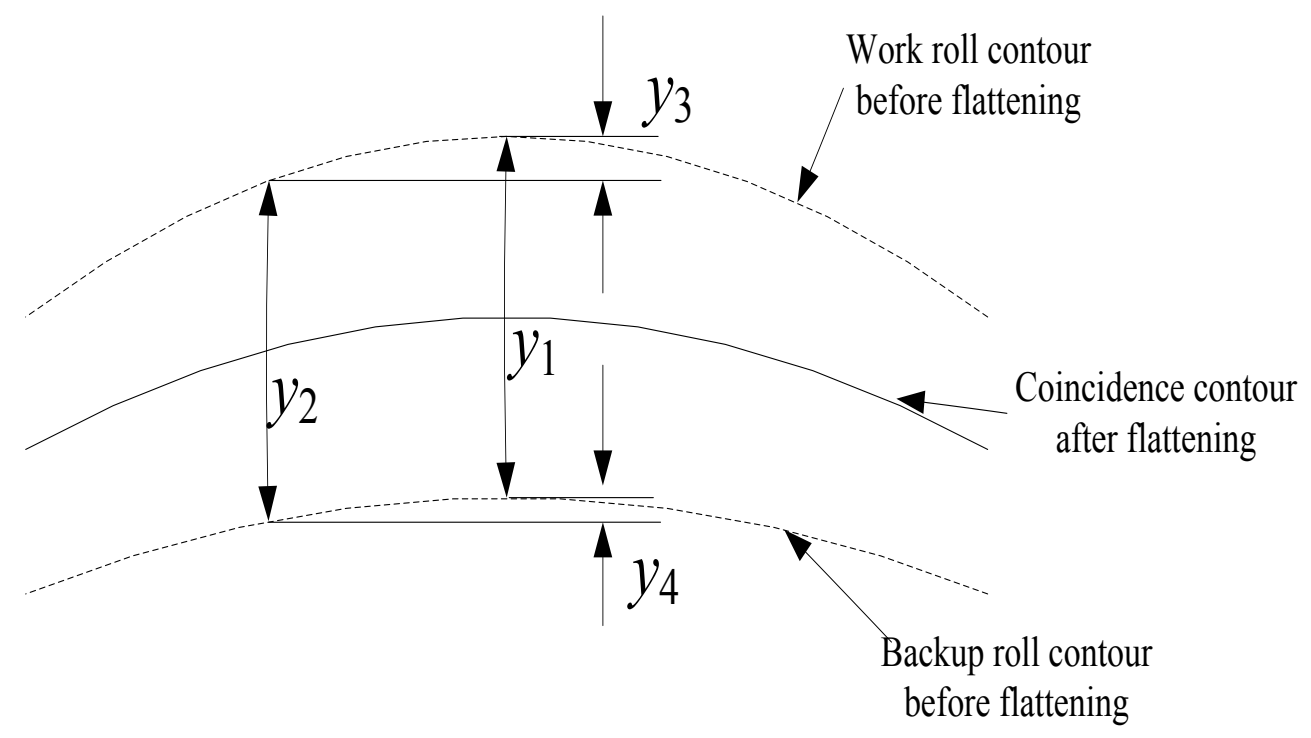

Fig. (4). Geometric coordination relations between work roll and backup roll.

By three dimension strip deformation model and roll deformation model rolling force axial distribution can be obtained which needs considerable computing time and cannot realize online application. According to basic law, this paper assumes that the rolling force distribution is quadratic as below:

$p(x)=a_{1} x^{2}+a_{2} x+a_{3}-B / 2 \leq x \leq B / 2$

Where, $a_{1}, a_{2}$, and $a_{3}$ are quadratic distribution coefficients. $A_{\mathrm{p}}$ is the rolling force distribution coefficient, which indicates the ratio of midpoint rolling force and average rolling force.

$$
\begin{aligned}
& A_{p}=\frac{p(0)}{p_{a}} \\
& p_{a}=\left(P_{b d}+P_{b o}-F_{w d}-F_{w o}\right) / B
\end{aligned}
$$

Where, $p(0)$ is the midpoint element rolling force, $p_{\mathrm{a}}$ is the average rolling force, $p_{\mathrm{bd}}$ is the rolling force in driver side, $p_{\text {bo }}$ is the rolling force in operating side, $F_{\mathrm{wd}}$ is the bending force in driver, and $F_{\text {wo }}$ is the bending force on operating side.

At the same time, rolling force distribution must meet the force balance and torque balance relationship as follows:

$$
\begin{aligned}
& P_{b d}+P_{b o}-F_{w d}-F_{w o}-\int p(x) d x=0 \\
& \left(P_{b d}-P_{b o}\right) \frac{L_{h}}{2}-\left(F_{w d}-F_{w o}\right) \frac{L_{f}}{2}+\left(F_{w d}+F_{w o}\right) S_{f} \\
& +\int x p(x) d x=0
\end{aligned}
$$
follows:

$$
\left\{\begin{array}{l}
a_{1}=12\left(1-A_{p}\right)\left(P_{b d}+P_{b o}-F_{w d}-F_{w o}\right) / B^{3} \\
a_{2}=-6\left[\begin{array}{l}
\left(P_{b d}-P_{b o}\right) L_{h}-\left(F_{w d}-F_{w o}\right) \\
L_{f}+2\left(F_{w d}+F_{w o}\right) S_{f}
\end{array}\right] / B^{3} \\
a_{3}=A_{p}\left(P_{b d}+P_{b o}-F_{w d}-F_{w o}\right) / B
\end{array}\right.
$$

When $a_{1}, a_{2}$, and $a_{3}$ are achieved by equation (26), the rolling force distribution is also obtained, and $A_{\mathrm{p}}$ can be optimized by iterative process in roll deformation model.

\subsection{Roll Integrated Contour}

Roll integrated contour includes grinding contour, wear contour and thermal contour [11]. Grinding contour is design contour for grinding machine, usually including sine curve, quadratic curve, third order curve and other high order curves. Wear contour and thermal contour are predicted by shape setup model and corrected by measured data. Roll integrated contour is calculated as follows:

$C(x)=C_{g}(x)+C_{w}(x)+C_{t}(x)$

Where, $C(x)$ is the roll integrated contour, $C_{\mathrm{g}}(x)$ is the roll grinding contour, $C_{\mathrm{w}}(x)$ is the roll wear contour, and $C_{\mathrm{t}}(x)$ is the roll thermal contour.

\subsection{Deformation Coordination Equation}

Work roll and backup roll are in contact with each other. Relationships among roll bending, flattening and roll contour are coordinated under bending force and rolling force. The coordination schematic diagram between work roll and backup roll is shown in Fig. (4) and the geometric relations between them are as follows: 


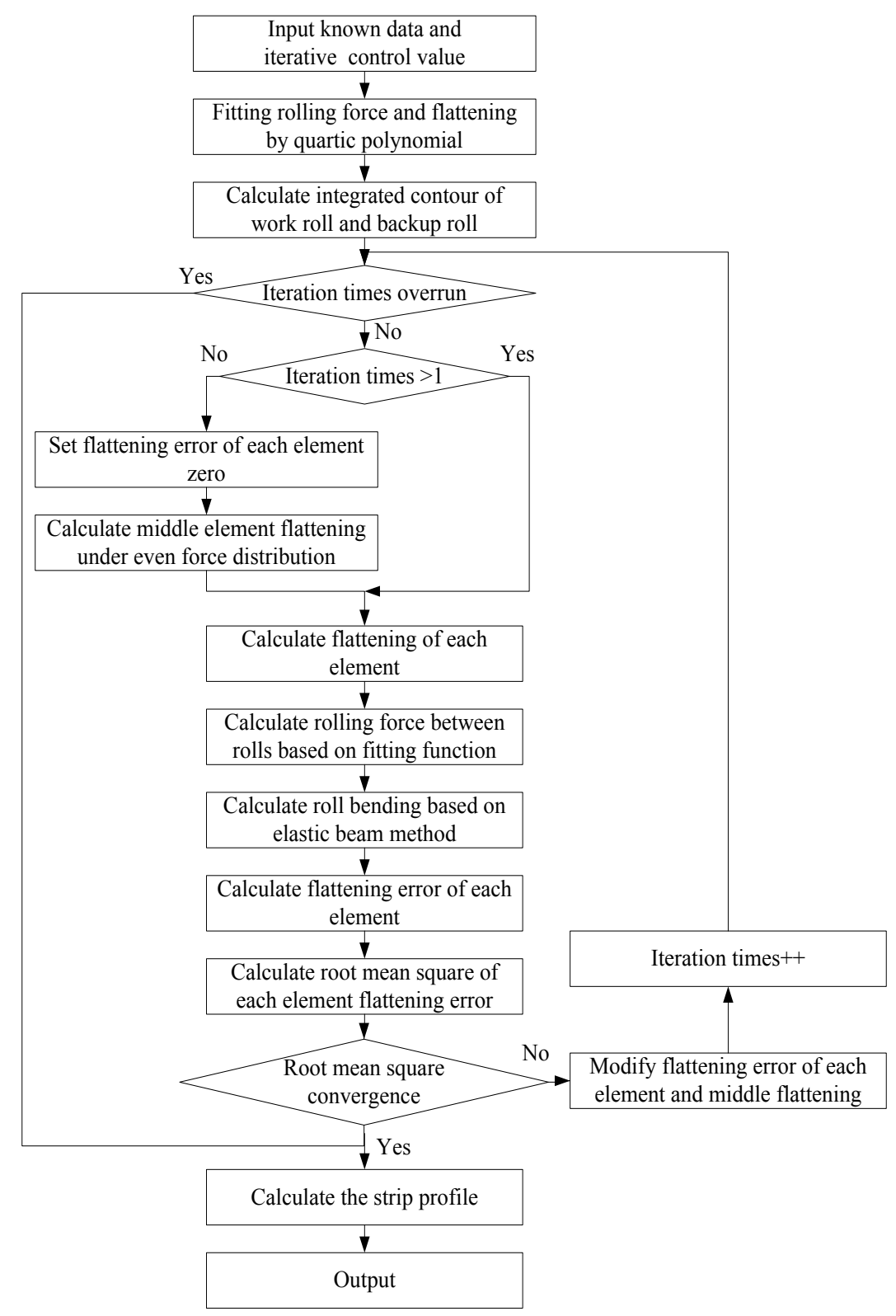

Fig. (5). Improved iterative process schematic diagram.

$y_{2}=y_{1}+y_{4}-y_{3}$

$y_{1}=y_{w b}(0)$

$y_{2}=y_{w b}(i)$

$y_{3}=-y_{w}(i)+C_{w}(i)$

$y_{4}=-y_{b}(i)-C_{b}(i)$

$y_{w b}(i)=y_{w b}(0)+\left(-y_{b}(i)-C_{b}(i)\right)$

$-\left(-y_{w}(i)+C_{w}(i)\right)$

Where, $y_{\mathrm{wb}}(i)$ represents flattening between work roll and backup roll of $\mathrm{i}$ element, $y_{\mathrm{b}}(i)$ is the backup roll bending of $i$ element, $C_{\mathrm{b}}(i)$ is the backup roll integrated contour of $i$ element, $y_{\mathrm{w}}(i)$ is the work roll bending of $i$ element, and $C_{\mathrm{w}}(i)$ is the work roll integrated contour of $i$ element.

\subsection{Improved Iterative Process}

Influence function method used two layer nested iteration, where rolling force distribution between rolls is inner iteration and middle flattening between rolls is outer iteration. When beginning outer iteration, the balance of inner iteration is broken and needs new iteration calculation. Due to the coupling relationship among the middle flattening, each element flattening and rolling force distribution between rolls, each element flattening error caused by rolling force and middle flattening is corrected at the same time, which improves the iterative efficiency. The improved iterative process is shown in Fig. (5). 


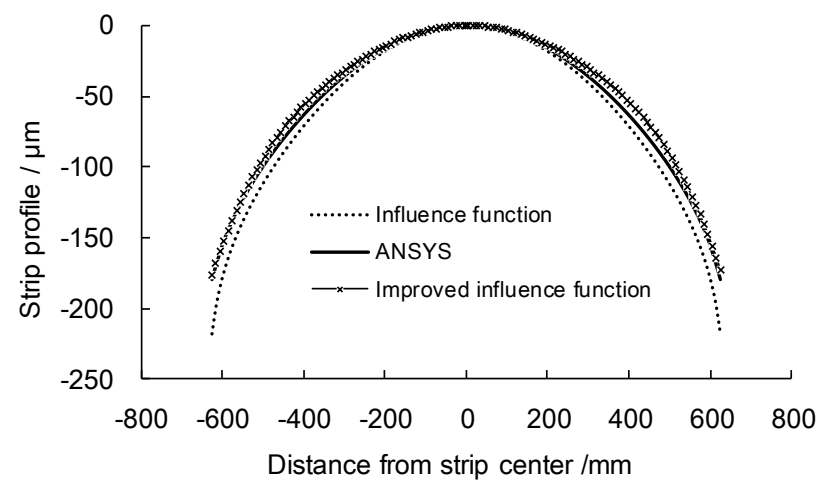

Fig. (6). Roll deformation calculation result comparison with ANSYS and influence function.

\section{CALCULATION RESULT VERIFICATION}

In order to verify calculation accuracy and speed of the improved influence function method for roll deformation, same conditions were obtained for comparison with other methods, including ANSYS and influence function method, the conditions are as follows:

1) Roll size. $D_{\mathrm{b}}=1540 \mathrm{~mm}, D_{\mathrm{w}}=660 \mathrm{~mm}, L_{\mathrm{b}}=1700 \mathrm{~mm}$, $L_{\mathrm{w}}=2000 \mathrm{~mm}, L_{\mathrm{h}}=2740 \mathrm{~mm}, L_{\mathrm{f}}=2980 \mathrm{~mm}, E_{\mathrm{w}}=E_{\mathrm{b}}=210 \mathrm{GPa}$, $v=0.3$.

2) Rolling process parameters. Total rolling force $P=13000 \mathrm{kN}$, bending force per side $F_{\mathrm{w}}=600 \mathrm{kN}, B=1250$ $\mathrm{mm}, S_{\mathrm{f}}=0 \mathrm{~mm}$, work roll radius grinding contour $C_{\mathrm{wg}}=-100$ $\mu \mathrm{m}$, and backup roll radius grinding contour $C_{\mathrm{bg}}=0 \mu \mathrm{m}$. Wear contour and thermal contour are not considered.

Comparison result is as shown in Fig. (6), improved influence function method has the same calculation accuracy as the other methods, especially the same as ANSYS which used three dimensions finite method. Based on the same hardware conditions, ASNSY needs 23 minutes, influence function method needs 0.713 seconds, and the improved influence function method only needs 0.037 seconds.

\section{CONCLUSION}

In this paper, a new roll deformation model is developed based on improved influence function method, which used new algorithm in roll bending, roll flattening and iterative process, and achieved good accuracy and rapid calcula- tion speed and also met the shape control system online application requirements. Comparison results with ANSYS and influence function methods show that the new model is reliable and running time consumption is considerably less than the other methods.

\section{CONFLICT OF INTEREST}

The authors confirm that this article content has no conflict of interest.

\section{ACKNOWLEDGEMENTS}

This work was supported by Beijing Higher Education Young Elite Teacher Project (YETP0413) and Technology Development Plan of Guangxi Province (2013AA01001).

\section{REFERENCES}

[1] J. Shao, A. R. He, Q. Yang, and N. A. Shi, "Simulation and application of shape setup control system in hot strip mill", J. Iron Steel Res., vol, 20, pp. 53-56, Jun 2008.

[2] A. Hacquin, P. Montmitonne, and J. P. Guillerault, "Threedimensional semi-analytical model of rolling stand deformation with finite element validation", Eur. J. Mech., vol. 17, pp. 79-106, January 1998.

[3] Z. H. Bai, Y. F. Jiang, X. D. Li, G. Z. Gang, F. P. Chen, and J. C. Lian, "Kiss between roller ends in skin rolling process of super thin strip", Chin. J. Mech. Eng., vol. 42, pp. 224-228, August 2006.

[4] X. L. Chen, and J. X. Zou, "A special finite element model for investigating controlling factors affecting behavior of rolls and strip flatness", In: Proceeding of the $4^{\text {th }}$ International Steel Rolling Conference, pp. 1-7, 1987.

[5] K. N. Shohet, and N. A. Townsend, "Roll bending methods of crown control in four-high plate mills", J. Iron Steel Inst., vol. 206, pp. 1088-1098, November 2002.

[6] P. Montmitonnet, "Hot and cold strip rolling process", Comput. Meth. Appl. Mech. Eng., vol. 195, pp. 6604-6625, October 2006.

[7] M. Salimi, and M. R. Forouzan, "Determination of bending actuators set points to control crown and flatness in hot rolling of strip", J. Mat. Process., vol. 125, pp. 670-677, September 2002

[8] X. F. Liu and L. Y. Wang, "Analysis of elastic deformation of rollers system in rolling mill based on influential function and prediction of plate shape", J. Chongqing Univ., vol. 23, pp. 87-90, November 2000

[9] S. P. Timoshenko and J. M. Gere, Mechanics of Materials., Science Press, 1978

[10] G. D. Wang, Shape Control and Shape Theory. Beijing: Metallurgical Industry Press, 1986.

[11] J. Shao, A. R. He, Q. Yang, and N. A. Shi, "Simulation and application of shape setup control system in hot strip mill", J. Iron Steel Res., vol. 20, pp. 53-56, June 2008.

Received: September 16, 2014

(C) Jian et al.; Licensee Bentham Open.

This is an open access article licensed under the terms of the Creative Commons Attribution Non-Commercial License (http://creativecommons.org/licenses/ by-nc/4.0/) which permits unrestricted, non-commercial use, distribution and reproduction in any medium, provided the work is properly cited. 